\title{
Analysis of Water Extraction From Lunar Regolith
}

U. Hegde and R. Balasubramaniam

National Center for Space Exploration Research, Glenn Research Center, Cleveland, Ohio

S. Gokoglu

Glenn Research Center, Cleveland, Ohio 


\section{NASA STI Program . . . in Profile}

Since its founding, NASA has been dedicated to the advancement of aeronautics and space science. The NASA Scientific and Technical Information (STI) program plays a key part in helping NASA maintain this important role.

The NASA STI Program operates under the auspices of the Agency Chief Information Officer. It collects, organizes, provides for archiving, and disseminates NASA's STI. The NASA STI program provides access to the NASA Aeronautics and Space Database and its public interface, the NASA Technical Reports Server, thus providing one of the largest collections of aeronautical and space science STI in the world. Results are published in both non-NASA channels and by NASA in the NASA STI Report Series, which includes the following report types:

- TECHNICAL PUBLICATION. Reports of completed research or a major significant phase of research that present the results of NASA programs and include extensive data or theoretical analysis. Includes compilations of significant scientific and technical data and information deemed to be of continuing reference value. NASA counterpart of peer-reviewed formal professional papers but has less stringent limitations on manuscript length and extent of graphic presentations.

- TECHNICAL MEMORANDUM. Scientific and technical findings that are preliminary or of specialized interest, e.g., quick release reports, working papers, and bibliographies that contain minimal annotation. Does not contain extensive analysis.

- CONTRACTOR REPORT. Scientific and technical findings by NASA-sponsored contractors and grantees.
- CONFERENCE PUBLICATION. Collected papers from scientific and technical conferences, symposia, seminars, or other meetings sponsored or cosponsored by NASA.

- SPECIAL PUBLICATION. Scientific, technical, or historical information from NASA programs, projects, and missions, often concerned with subjects having substantial public interest.

- TECHNICAL TRANSLATION. Englishlanguage translations of foreign scientific and technical material pertinent to NASA's mission.

Specialized services also include creating custom thesauri, building customized databases, organizing and publishing research results.

For more information about the NASA STI program, see the following:

- Access the NASA STI program home page at http://www.sti.nasa.gov

- E-mail your question via the Internet to help@ sti.nasa.gov

- Fax your question to the NASA STI Help Desk at $443-757-5803$

- Telephone the NASA STI Help Desk at 443-757-5802

- Write to: NASA Center for AeroSpace Information (CASI) 7115 Standard Drive Hanover, MD 21076-1320 
NASA/TM-2012-217441

AIAA-2012-0634

\section{Analysis of Water Extraction From Lunar Regolith}

\section{U. Hegde and R. Balasubramaniam}

National Center for Space Exploration Research, Glenn Research Center, Cleveland, Ohio

S. Gokoglu

Glenn Research Center, Cleveland, Ohio

Prepared for the

50th Aerospace Science Conference

sponsored by the American Institute of Aeronautics and Astronautics

Nashville, Tennessee, January 9-12, 2012

National Aeronautics and

Space Administration

Glenn Research Center

Cleveland, Ohio 44135 


\section{Acknowledgments}

The authors gratefully acknowledge the support of this work by the In-Situ Resource Utilization Project which is a part of the NASA Exploration Technology Development Program. U. Hegde and R. Balasubramaniam were supported under NASA Contract No. NNC08BA08B with the National Center for Space Exploration Research. The authors greatly appreciate the encouragement and

insights offered by D. Linne and K. Sacksteder of the NASA Glenn Research Center. The authors thank A. Paz and L. Oryschyn of the NASA Johnson Space Center for providing results of their vaporization experiments.

Level of Review: This material has been technically reviewed by technical management.

Available from

NASA Center for Aerospace Information 7115 Standard Drive

Hanover, MD 21076-1320
National Technical Information Service 5301 Shawnee Road Alexandria, VA 22312

Available electronically at http://www.sti.nasa.gov 


\title{
Analysis of Water Extraction From Lunar Regolith
}

\author{
U. Hegde and R. Balasubramaniam \\ National Center for Space Exploration Research \\ Glenn Research Center \\ Cleveland, Ohio 44135 \\ S. Gokoglu \\ National Aeronautics and Space Administration \\ Glenn Research Center \\ Cleveland, Ohio 44135
}

\begin{abstract}
Distribution of water concentration on the Moon is currently an area of active research. Recent studies suggest the presence of ice particles, and perhaps even ice blocks and ice-cemented regolith on the Moon. Thermal extraction of the in-situ water is an attractive means of satisfying water requirements for a lunar mission. In this paper, a model is presented to analyze the processes occurring during the heat-up of icy regolith and extraction of the evolved water vapor. The wet regolith is assumed to be present in an initially evacuated and sealed cell which is subsequently heated. The first step of the analysis involves calculating the gradual increase of vapor pressure in the closed cell as the temperature is raised. Then, in the second step, the cell is evacuated to low pressure (e.g., vacuum), allowing the water vapor to leave the cell and be captured. The parameters affecting water vapor pressure build-up and evacuation for the purpose of extracting water from lunar regolith are discussed in the paper. Some comparisons with available experimental measurements are also made.
\end{abstract}

\section{Nomenclature}

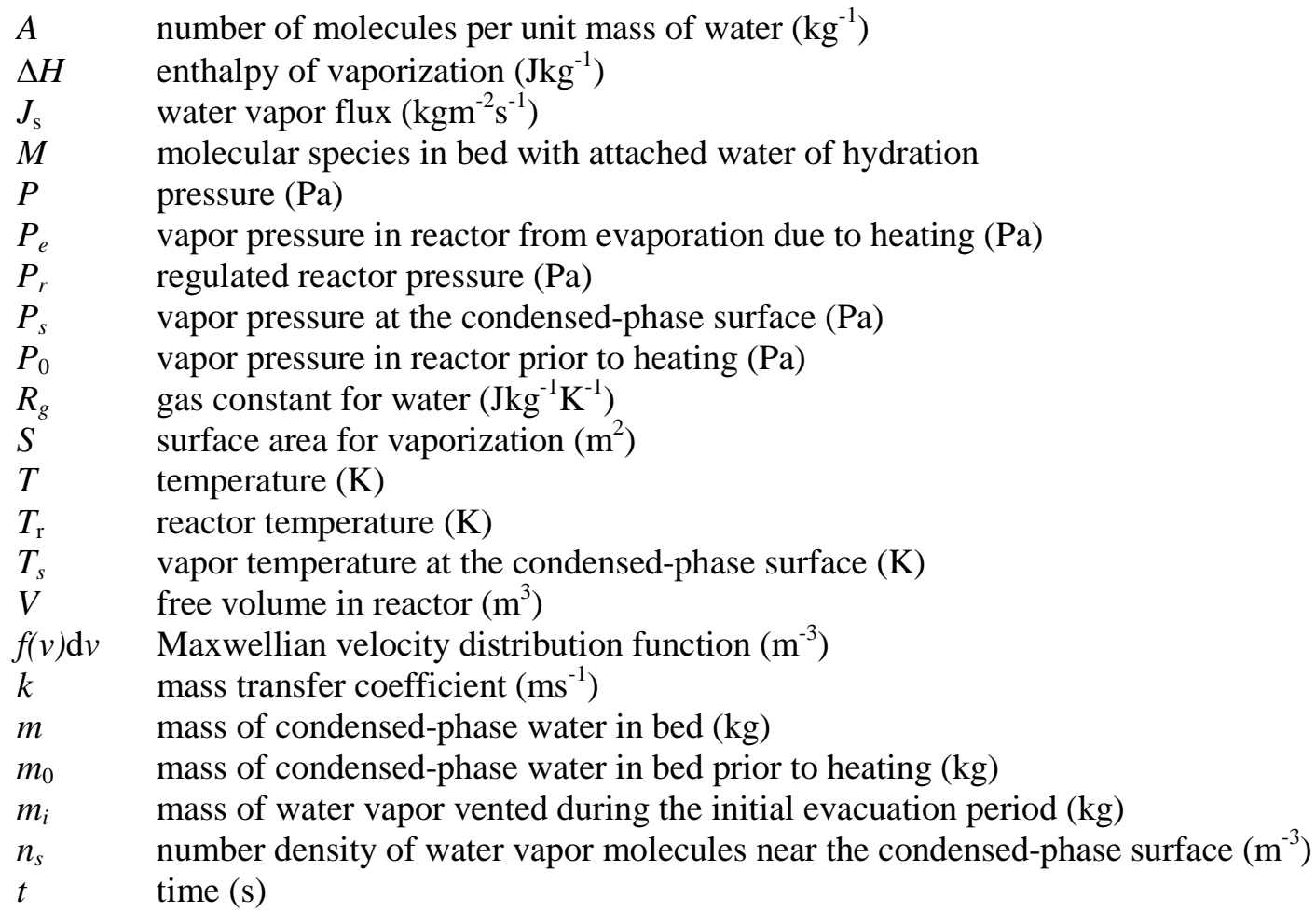




$\begin{array}{ll}t_{\mathrm{c}} & \text { time constant for evaporation (s) } \\ v & \text { velocity }\left(\mathrm{ms}^{-1}\right) \\ \lambda_{e} & \text { evaporation coefficient } \\ \rho_{0} & \text { density of water vapor in the reactor prior to heating }\left(\mathrm{kgm}^{-3}\right) \\ \rho_{s} & \text { density of water vapor at the condensed phase surface }\left(\mathrm{kgm}^{-3}\right) \\ \rho_{r} & \text { density of water vapor in the reactor }\left(\mathrm{kgm}^{-3}\right)\end{array}$

\section{Introduction}

A major objective of lunar in-situ resource utilization (ISRU) (Refs. 1 to 3) is production of water and oxygen from lunar regolith. To this end, the distribution of water concentration on the Moon continues to be an area of active research. Hydrogen concentrations, at least some of which were presumed to indicate the presence of water, were observed near the lunar poles using remote neutron scattering (Ref. 4). More recently, the Lunar Crater Observation and Sensing Satellite (LCROSS) mission (Ref. 5) indicated water concentrations in the range of $5.6 \pm 2.9$ percent by mass at the impact site in the permanently shadowed region of the crater Cabeus at the lunar south pole. It is believed that the ice may be present in the form of ice particles, ice-cemented regolith and even ice blocks. Away from the poles and in sunlit areas of the Moon, spectroscopic measurements have shown hydroxyl and water absorption at many locations. Since any surface water in regions exposed to the sun is unstable and would have sublimated, the observed signals are interpreted as arising from water adsorbed at the surface or present within the interstices of the lunar regolith. The absorption signals indicate a trapped water content of 10 to $1000 \mathrm{ppm}$.

A thermal process where the icy or water-containing regolith is heated to remove the water in the for of vapor may be utilized for water extraction. There are differences in the physical processes that occur depending upon whether the water is in the form of ice (either as icy particles or regolith-ice blends) or bound within the regolith particles. In the case of regolith-ice blends, heat addition primarily creates a transformation of the ice to the vapor phase which may be removed. The physical transformation in the general case is

$$
\mathrm{H}_{2} \mathrm{O}(\text { ice }) \rightarrow \mathrm{H}_{2} \mathrm{O}(g)
$$

with or without an intermediate liquid phase depending upon the ambient conditions. In the case of bound water, the heat addition must first break any bonds between the water molecules and other molecules inside the regolith particle (e.g., water may be in the form of water of hydration attached to a different molecule), i.e.,

$$
M \bullet\left(x \mathrm{H}_{2} \mathrm{O}\right) \rightarrow M+x \mathrm{H}_{2} \mathrm{O}
$$

Subsequently, the water molecules must diffuse out of the particle and then be removed utilizing , for example, a carrier gas. The vaporization process for the icy regolith can be carried out at lower temperatures (i.e., 100 to $150{ }^{\circ} \mathrm{C}$ ) than the extraction of bound water which typically requires temperatures in excess of $250^{\circ} \mathrm{C}$ in order to break the bonds of hydration.

The NASA project RESOLVE (Regolith \& Environment Science and Oxygen \& Lunar Volatile Extraction) (Ref. 6) is being designed to extract water from both the icy-regolith blends as well as that bound within the regolith particles. A batch process is envisioned where a given amount of lunar regolith is deposited inside a tubular reactor. The reactor walls are heated to raise the regolith to the desired temperature. For the case of the icy regolith, the reactor is vented once there is sufficient vapor pressure build-up and the water is captured downstream. For the case of bound water, the regolith is heated as before but to a higher temperature as noted above. An inert carrier gas, e.g., argon, is flowed in order to remove the water diffusing out of the particles.

The RESOLVE project will also investigate extraction of water using hydrogen reduction of the oxides in the regolith particles. The hydrogen reduction method targets mainly the iron oxide in the 
regolith. Iron oxide occurs in lunar regolith as ilmenite, particularly in titanium-rich basalts, or may be found dispersed in the glassy phase of lunar regolith particles. The overall gas-solid reaction between FeO and hydrogen is given by:

$$
\mathrm{FeO}+\mathrm{H}_{2} \Leftrightarrow \mathrm{Fe}+\mathrm{H}_{2} \mathrm{O}
$$

The formed water may be electrolyzed in an electrolyzer subsystem to produce oxygen and recycle the hydrogen.

While thermal and hydrogen reduction systems are well developed for Earth applications, in the lunar context it is important to establish a favorable balance between efficiency, robustness, and equivalent system mass in order to conserve resources. The reactor must interface with the other subsystem processes such as upstream regolith extraction and downstream electrolysis and phase separation. A need exists, therefore, to establish an analytical framework to couple these subsystems together. The building blocks of this framework are the individual subsystem models.

The development of a generalized analytical model of the hydrogen reduction reactor subsystem and its validation against experimental data from reduction of JSC-1A, a lunar regolith simulant, has been discussed in earlier papers (Ref. 7). The overall objective of this paper is to model water extraction from icy regolith in a tubular reactor geometry similar to that envisioned for the RESOLVE project. The extraction process is formulated in terms of the following two steps: (i) water vapor evolution and pressure build-up in the closed reactor as it is heated, and (ii) venting of the vapor to a secondary reservoir maintained at a suitable (lower) pressure. The key parameter appearing in the model is a characteristic time (i.e., time constant) for evaporation which depends upon the evaporating surface area, the resistance of the regolith bed to vapor transport, and the free volume available to the vapor.

In the following, the model development is discussed first. Then, calculated results from the model are presented. These include the effects of different values of the time constant, reactor temperature and vent pressure on the vapor generation and ice depletion rate. Qualitative comparison with initial experimental results on the vapor pressure build-up are also provided.

\section{Model Description}

The water extraction process begins by filling the empty reactor with the desired amount of icy regolith. The reactor is then sealed. The walls of the reactor are heated externally. During this heating period, the temperature of the regolith increases. Water vapor is given off and accumulates in the free volume of the reactor. When the water vapor pressure reaches a pre-determined level or the system reaches equilibrium, the vapor is vented into a reservoir where it may be condensed to liquid. The model addresses both of these aspects.

\section{Pressure Rise Due to Vapor Build-Up}

At the surface of the condensed phase (i.e., ice or liquid water) it may be assumed that there is thermodynamic equilibrium which yields a unique relation for the vapor pressure in terms of the temperature. This is given by the Clausius-Clapeyron relation (Ref. 8)

$$
\frac{d P}{P}=\frac{\Delta H}{R_{g} T^{2}} d T
$$

The vapor pressure difference at the surface of the condensate and in the free volume of the reactor is the driving force for continued evaporation of the condensed phase. The vapor mass transfer from the regolith bed to the free volume of the reactor is hindered by the depth of the bed which resists the transport. 
Thus, apart from the amount of ice present initially in the dirt sample, parameters important for the analysis are:

(a) bed/reactor temperature: increasing the temperature will increase the vapor pressure at the particle surface, thereby increasing the driving force for evaporation,

(b) free volume: increasing the free volume will lead to reduced partial pressure of water vapor in the free volume, thereby increasing the driving force for evaporation, and allowing for an increased amount of water vapor collection,

(c) mass transfer coefficient: decreasing the mass transfer coefficient (thereby increasing the resistance of the dirt bed to water vapor transport) will decrease the vaporization rate, and

(d) surface area of the condensed phase: increasing the surface area of the condensed phase will increase the area over which vaporization takes place. The overall amount of ice/dirt also contributes to the surface area.

The model considers the regolith bed as a lumped unit which is suitable for well-mixed beds during operation. If, for example, a sufficiently deep dirt bed happens to remain stationary during operation then the upper layers of the dirt in contact with the free volume may dry out faster, and the analysis of spatial variations of the water vapor profile in the bed may be warranted.

The model is developed by first considering the case where evaporation takes place to vacuum (Ref. 9) and then generalizing to a nonzero vapor pressure in the reactor. The number density of the water molecules at the condensed phase surface is related to the corresponding vapor density by Avogadro's Law so that

$$
n_{s}=A \rho_{s}
$$

The single component Maxwellian distribution function yields the number of molecules with velocity $v$ in the velocity space $\mathrm{d} v$

$$
f(v) d v=\frac{n_{s}}{\left(2 \pi R_{g} T_{s}\right)^{1 / 2}} \exp \left(-\frac{v^{2}}{2 R_{g} T_{s}}\right) d v
$$

where $v$ represents the component of the velocity in the direction of the outward normal to the evaporating surface. This expression may be used to evaluate the number of molecules evaporating from the surface.

Define an evaporation coefficient $\lambda_{\mathrm{e}}$ which represents the fraction of molecules that do not return to the surface. Then the flux of water vapor from the evaporating surface is given by the half-range integral

$$
J_{s}=\lambda_{e} \rho_{s} \int_{0}^{\infty} \frac{v}{\left(2 \pi R_{g} T_{s}\right)^{1 / 2}} \exp \left(-\frac{v^{2}}{2 R_{g} T_{s}}\right) d v
$$

which simplifies to

$$
J_{s}=\lambda_{e} \rho_{s} \sqrt{\frac{R_{g} T_{s}}{2 \pi}}
$$

The rate of change of condensed-water mass evaporating into vacuum may therefore be written as

$$
\frac{d m}{d t}=-k S \rho_{s}
$$


where the factor $k$ is given by

$$
k=\lambda_{e} \sqrt{\frac{R_{g} T_{s}}{2 \pi}}
$$

For the case when the vapor pressure in the reactor is nonzero, the equation for $m$ is generalized by modifying Equation (6) to include this effect, i.e.,

$$
\frac{d m}{d t}=-k S\left(\rho_{s}-\rho_{r}\right)
$$

where $\rho_{s}$ and $\rho_{r}$, are the densities of the surface vapor and the bulk reactor vapor, respectively, and are related to their separate vapor pressures as well as the overall vapor temperature (assumed to be the same as the reactor temperature) by the equation of state. Since vaporization is not freely into vacuum, the factor $k$ is identified as a mass transfer coefficient which accounts for the resistance resulting from the finite reactor pressure and bed depth and has units of velocity. In general, $k$, or the time constant, $t_{c}$, defined later, is expected to be determined experimentally.

If $m_{o}$ is the initial mass of condensed water in the dirt and the initial density of vapor in the free volume is $\rho_{0}$, the quantity $\rho_{r}$ may be expressed as

$$
\rho_{r}=\rho_{0}+\frac{\left(m_{0}-m\right)}{V}
$$

and the equation for the mass of the condensed phase in the reactor, $m$, becomes

$$
\frac{d m}{d t}+\frac{k S}{V} m=-k S\left(\rho_{s}-\left(\rho_{0}+\frac{m_{0}}{V}\right)\right)
$$

Once $m$ is determined from the integration of Equation (10), the vapor density in the reactor is obtained by Equation (9).

It is assumed that the mass flux of evaporating water is not large enough relative to the thermal mass of the regolith simulant to cool the surface temperature due to the removal of the latent heat of vaporization. This assumption eliminates the coupling between heat and mass transport processes. If needed, however, an energy equation for the temperature change can be coupled with the vaporization rate equation. For the purposes of this paper the temperature-time history of the reactor will be assumed to be provided. Note that, in general, the quantities $k, S$, and $V$ are time-dependent. For example, even for a fixed reactor temperature, as the ice coating thins out by evaporation, the resistance to vapor transport may change thereby modifying the factor $k$. At the same time, the surface area for evaporation, $S$, may also change.The free volume may also be altered if the bed void fraction changes due to evaporation of the condensed water. However, in order to obtain an estimate of the evaporation rate the factors $k$, $S$, and $V$ may be assumed constant during the evaporation process. If the reactor temperature is also fixed the following solution for $m$ is obtained

$$
\frac{\left(m_{0}-m\right)}{V}=\left(\rho_{s}-\rho_{0}\right)\left(1-\exp \left(-\frac{k S}{V} t\right)\right)
$$

It is clear from the above equation that the parameter

$$
t_{c}=\frac{V}{k S}
$$


is a characteristic time (i.e. time constant) for the evaporation process.

Assuming perfect gas behavior, the vapor pressure due to evaporation is given by

$$
P_{e}=\left(P_{s}-P_{0}\right)\left(1-\exp \left(-\frac{k S}{V} t\right)\right)
$$

or, equivalently,

$$
\frac{P_{e}}{\left(P_{s}-P_{0}\right)}=\left(1-\exp \left(-\frac{t}{t_{c}}\right)\right)
$$

In general, however, the vaporization rate equation must be solved numerically if the temperature changes during the evaporation process are to be accounted for.

\section{Evaporation During Reactor Venting}

The mass of vapor available in the free volume at the end of the heat-up cycle is $\rho_{\mathrm{r}} V$. This amount is generally much less than the water still present in the condensed phase. Thus, vaporization from the condensed phase will continue during the vent. It is assumed that the reactor is vented at a constant pressure, e.g., using a backpressure regulator. Thus, as vapor leaves the reactor, more condensed water evaporates to increase the vapor pressure in the reactor to the regulated value. After the initial vent, this may be modeled as a continuous process with the rate of evaporation given by Equation (8).

It is convenient to cast Equation (8) in terms of the saturation and regulated reactor pressures using the equation of state to yield

$$
\frac{d m}{d t}=-\frac{k S}{R_{g} T_{r}}\left(P_{s}-P_{r}\right)
$$

In terms of the time constant $t_{\mathrm{c}}$ and the free volume $V$ the above equation becomes

$$
\frac{d m}{d t}=-\frac{V}{t_{c} R_{g} T_{r}}\left(P_{s}-P_{r}\right)
$$

It is clear that for vaporization to take place the regulated-reactor pressure must be less than the saturation vapor pressure at the reactor temperature.

Let the mass of water removed when the reactor pressure is first relieved be $m_{\mathrm{i}}$. Then, if the time constant and $V$ are assumed to be constant during the vent process, the time for complete evaporation is given by

$$
t_{\text {evap }}=\frac{\left(m_{0}-m_{i}\right)}{\frac{d m}{d t}}
$$

Equations (16) and (17) may be written as

$$
\frac{d \hat{m}}{d \hat{t}}=-\frac{V}{\left(m_{0}-m_{i}\right) R_{g} T_{r}}\left(P_{s}-P_{r}\right)
$$

where the character $\wedge$ designates a nondimensional quantity with 


$$
\hat{t}_{\text {evap }}=\frac{1}{\frac{d \hat{m}}{d \hat{t}}}
$$

and

$$
\hat{m}=-\frac{m}{\left(m_{0}-m_{i}\right)}
$$

and

$$
\hat{t}=\frac{t}{t_{c}}
$$

The quantity $\left(m_{0}-m_{i}\right) / V$ is the effective density of the condensed-phase water if it occupied the free volume $V$ of the reactor. It is expected to be of the order of $100 \mathrm{~kg} / \mathrm{m}^{3}$ for the conditions to be encountered by the RESOLVE experiment.

\section{Results and Discussion}

\section{Effect of the Time Constant on Evaporation}

Equation (14) indicates that the vapor pressure in the closed reactor cannot exceed the saturation vapor pressure at constant temperature. The time constant, $t_{c}$, is a measure of how fast the vapor pressure in the reactor increases with time. A plot of Equation (14) is presented in Figure 1.

As $t_{c}$ increases, it takes longer for the vapor pressure in the reactor to build up. Equation (12) shows that $t_{c}$ is proportional to the free volume $V$ and inversely proportional to the mass transfer coefficient, $k$, and the effective surface area for vaporization, $S$. Thus, increasing the size of the reactor for a given loading of wet regolith will increase the time needed for the vapor pressure to grow to a desired level. The mass transfer coefficient, $k$, is a measure of the ease with which the vapor leaves the regolith bed. As $k$ increases the time constant decreases and there is a faster build-up of vapor pressure in the reactor. It may

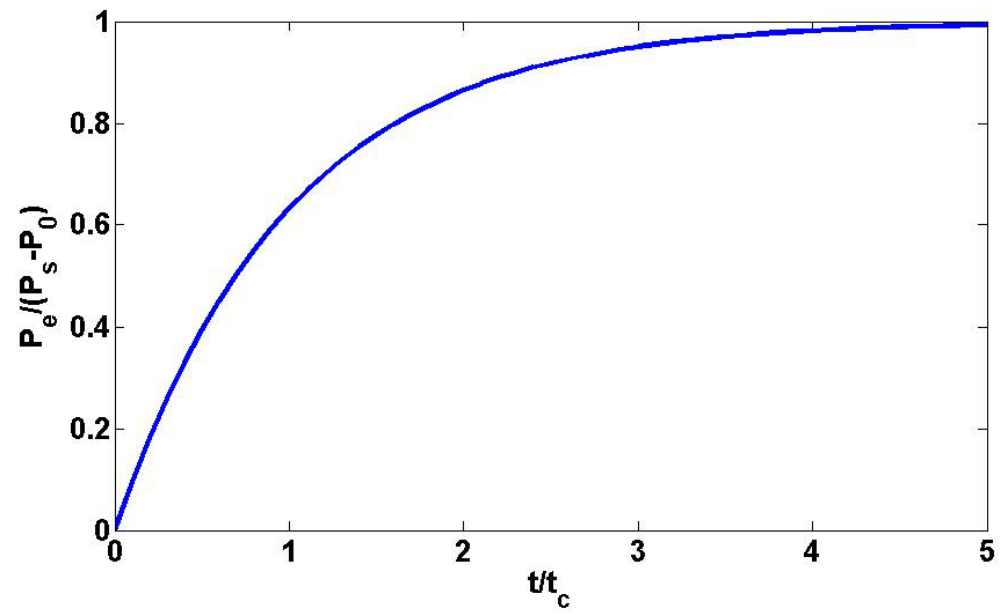

Figure 1.-Nondimensional vapor pressure increase in the reactor with time at a constant temperature. 


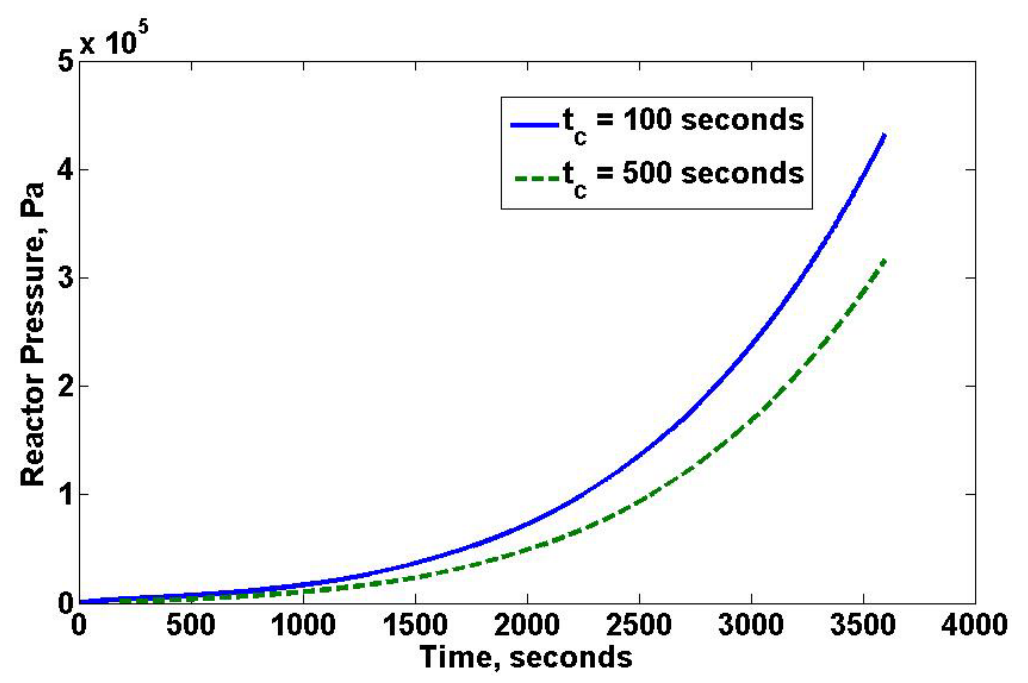

Figure 2.-Increase in reactor vapor pressure with time during heating for two different time constants.

be expected that $k$ will be larger for a continually agitated, well-mixed bed as opposed to a quiescent, stationary bed. For a well-mixed bed, it may be expected that the evaporation of the condensed water occurs on the surfaces of the individual particles of the regolith so that $S$ in this case is proportional to the surface area of the regolith particles. For a given amount of regolith, the surface area will be larger for smaller particles. Thus, there may be some benefit to load the reactor with relatively smaller particles. For the case where the regolith bed is stationary the effective surface area is expected to be related to the cross-sectional area of the reactor. In this case, evaporation may take place starting from the surface of the bed and progressing through the bed in layers. The spatial variation in condensed water fraction then has to be taken into account which will modify the analysis presented in the previous section.

For the case where the reactor temperature increases with time, Equation (10) must in general be solved numerically. Even if the parameters $V, k$, and $S$ are taken as constant during the heating, the saturation vapor density, $\rho_{s}$, remains a strong function of the temperature. In order to assess the effects of the time constant for the case of varying temperature, Equation (10) has been solved for the case of a linear increase in temperature with time. The corresponding variation of reactor pressure is plotted in Figure 2 for two different values of the time constant (i.e., $t_{c}=100 \mathrm{~s}$ and $t_{c}=500 \mathrm{~s}$, respectively). The temperature is assumed to increase linearly from $298 \mathrm{~K}\left(25^{\circ} \mathrm{C}\right)$ to $423 \mathrm{~K}\left(150^{\circ} \mathrm{C}\right)$ over $1 \mathrm{hr}$. The vapor pressure-temperature relationship needed for the calculations as expressed by Equation (1) have been modeled using the Hyland-Wexler correlation (Ref. 10) for liquid water.

As in the case of constant temperature, it is found that decreasing the time constant results in a more rapid rise in pressure. Comparing Figure 1 and Figure 2, it is also seen that for the case of varying temperature the pressure-time curve is concave upward whereas for the case of constant temperature the curve is concave downward. This shows that the rate of increase of vapor pressure in the reactor increases as the temperature rises whereas for the constant temperature case, the rate decreases with time as the vapor pressure builds inside the reactor.

The behavior of the vapor pressure-time curve predicted by the model and depicted in Figure 2 has been observed in experiments conducted at the NASA Johnson Space Center (JSC). In these experiments, JSC-1A, a lunar regolith simulant, with added water was placed in a small covered crucible and heated. The increase in pressure in the crucible was monitored. An example of the observed pressure-time behavior is shown in Figure 3. The experimental curve is seen to exhibit the concave up behavior similar to the model prediction. During the observation time the crucible temperature increased from approximately 273 to $423 \mathrm{~K}$. Further quantitative comparisons with the limited crucible experiments have not been carried out as the experimental efforts have now shifted to the development of the tubular reactor configuration for the RESOLVE experiment. 


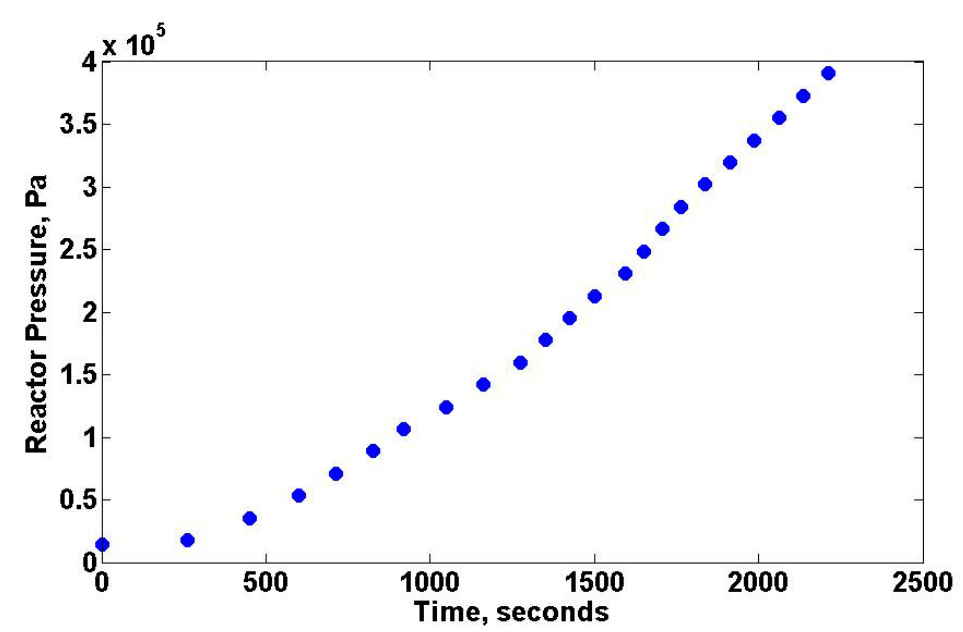

Figure 3.-Experimentally observed increase in vapor pressure with time during heating.

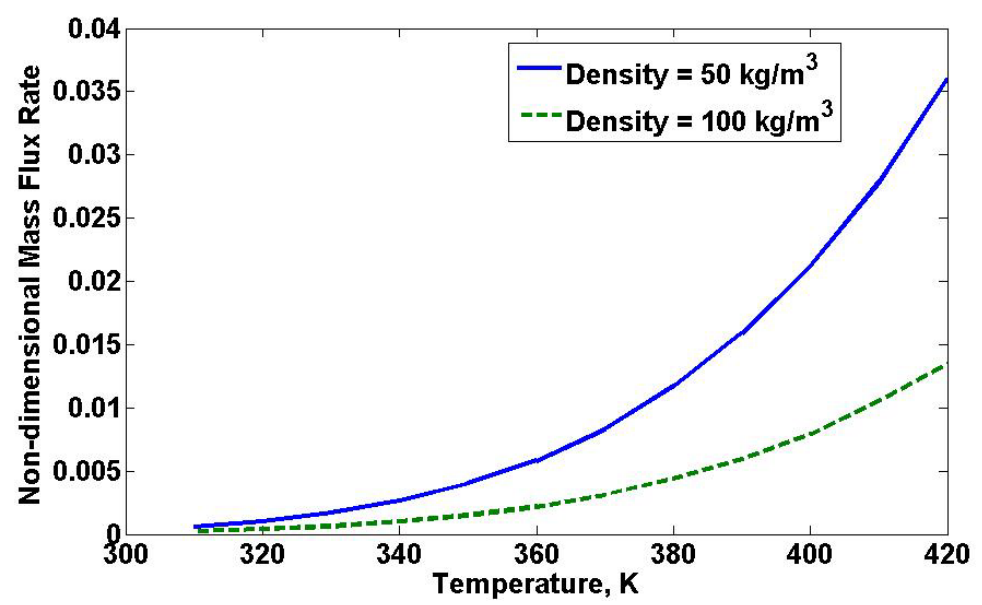

Figure 4.-Nondimensional water evaporation rate as a function of temperature for two different effective density parameter values.

\section{Effects of Reactor Temperature and Pressure on Evaporation During Venting}

According to Equation (1), the saturation pressure $P_{s}$ is a nonlinear function of the reactor temperature $T_{r}$. Assuming that the free volume of the reactor and the evaporation time constant do not change during the vent, Equation (16) indicates that the water evaporation rate is also a nonlinear function of the reactor temperature. This is shown in Figure 4 which plots the nondimensional evaporative mass rate as a function of the reactor temperature for two different values of the effective density parameter $\left(m_{0}-m_{i}\right) / V$. The corresponding values of the nondimensional evaporation time are plotted in Figure 5. Increase in the effective density parameter indicates a smaller value of the free volume for a given amount of condensed water in the reactor. Equation (18) shows that the evaporative mass flux rate is then reduced.

The water evaporation rate is proportional to the difference between the saturation vapor pressure, $P_{s}$, at the reactor temperature $T_{r}$, and the regulated reactor pressure $P_{r}$. If $P_{r}$ is much less than $P_{s}$ then the regulated pressure value is not important in the evaporation process. This is shown in Figure 6 which plots the nondimensional evaporation time as a function of reactor temperature for two different values of the regulated reactor pressure, i.e., 0.01 and $0.1 \mathrm{~atm}$, respectively. The density parameter for these calculations is taken to be $100 \mathrm{~kg} / \mathrm{m}^{3}$. At the lower temperatures, the evaporation time is relatively smaller for the 0.01 atm case. However, beyond approximately $350 \mathrm{~K}$ as the saturation pressure becomes much larger than 0.1 atm, there is an insignificant difference between the evaporation times for the 0.01 and 0.1 atm cases. 


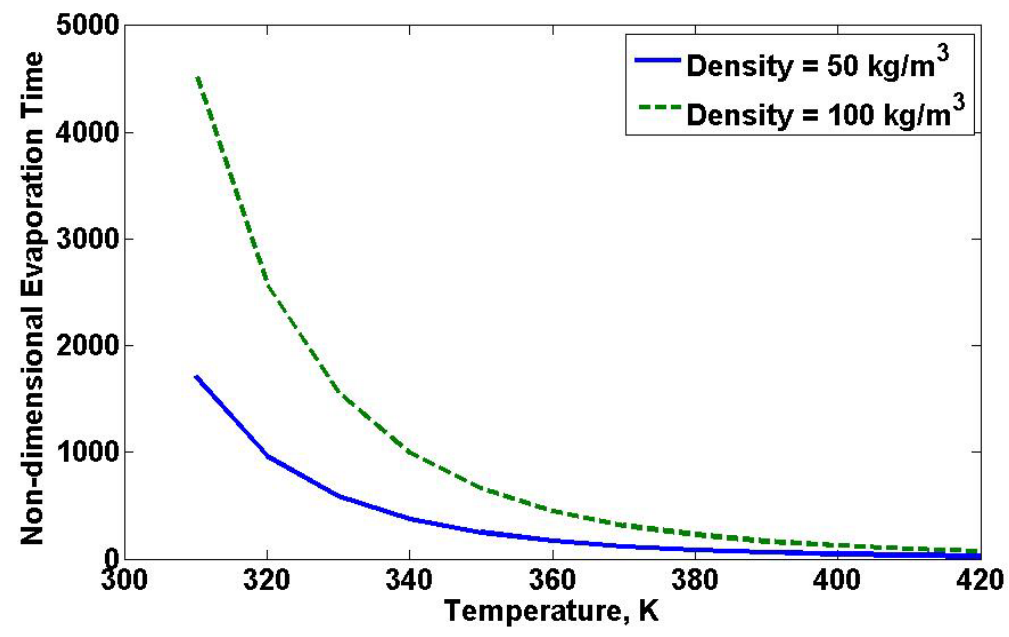

Figure 5.-Nondimensional water evaporation time as a function of temperature for two different effective density parameter values.

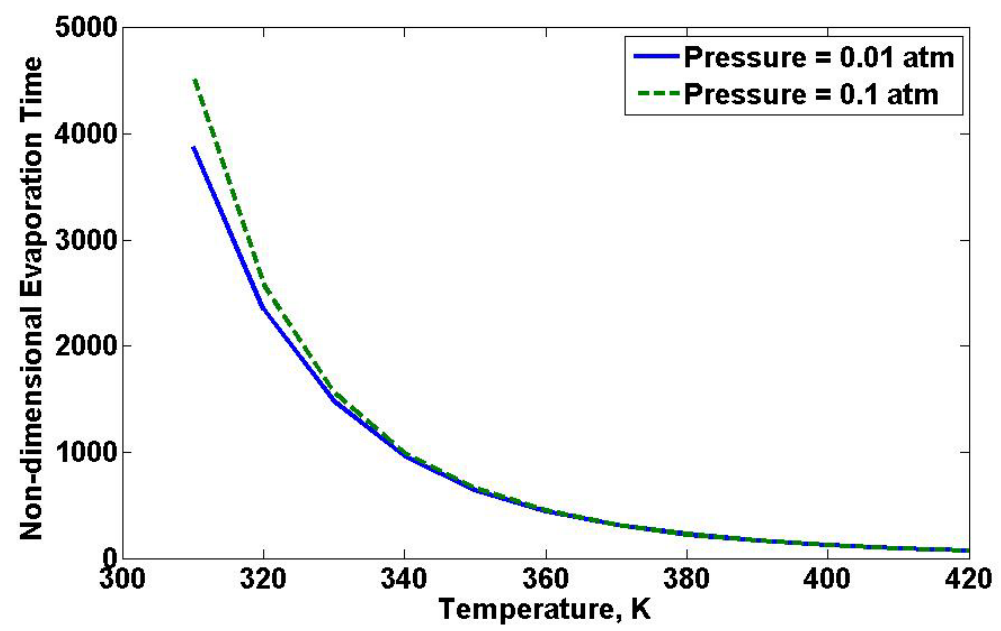

Figure 6.-Nondimensional water evaporation time as a function of temperature for two different regulated reactor pressure values.

\section{Conclusion}

A model has been developed to analyze the processes occurring during the heat-up of icy regolith and extraction of the evolved water vapor. The first part of the model calculates the vapor pressure increase in a closed cell containing the initially wet regolith as the temperature is raised and the second part analyzes the evaporation time and mass evaporation rate during reactor venting. The flux of water vapor from the evaporating surface to vacuum is first obtained and then the external vapor pressure is accounted for. The rate of increase of the vapor pressure during heat-up depends upon a characteristic time constant related to the free volume in the cell, the effective surface area for vaporization and a mass transfer coefficient.

Reducing the time constant increases the rate of vaporization. The shape of the vapor pressure-time curve obtained from the model is shown to be similar to that obtained experimentally. The evaporation time during the vent period depends strongly on the regolith temperature but is not sensitive to the pressure to which the reactor is vented as long as this pressure is much less than the saturation vapor pressure at the regolith temperature. 


\section{References}

1. Sanders, G. B., Larson, W. E., Sacksteder, K. R., and Mclemore, C., "NASA In-Situ Resource Utilization (ISRU) Project-Development \& Implementation,” AIAA Paper No. 2008-7853, AIAA SPACE 2008 Conference \& Exposition, San Diego, California, September 2008.

2. Larson, W. E., Sanders, G. B., Sacksteder, K. R., Simon, T. M., and Linne, D. L., “NASA’s In-Situ Resource Utilization Project: A Path to Sustainable Exploration,” IAC-08-A3.2.B13, International Astronautical Congress, Glasgow, Scotland, October 2008.

3. Sanders, G. B., Larson, W. E., Sacksteder, K. R., Simon, T. M., and Linne, D. L., “Open Architecture for Lunar Surface Systems-Challenges \& Opportunities In Design, Integration, And Partnerships,” IAC-08-D3.2.1, International Astronautical Congress, Glasgow, Scotland, October 2008.

4. Clark, R. N., "Detection of Adsorbed Water and Hydroxyl on the Moon,” Science, 326, 562-564 (2009).

5. Colaprete, A. et al, "Detection of Water in the LCROSS Ejecta Plume,” Science, 330, 463-468 (2010).

6. Sanders, G. B., Larson, W. E., Quinn, J. W., Picard, M., and Boucher, D., "RESOLVE for Lunar Polar Ice/Volatile Characterization Mission,”, EPSC-DPS2011-1605, 6 (2011).

7. Hegde, U., Balasubramaniam, R., and Gokoglu, S., "Development and Validation of a Model for Hydrogen Reduction of JSC-1A”, NASA TM-2009-215618, May 2009.

8. Cengel, Y. A., and Boles, M. A., Thermodynamics: An Engineering Approach, First Edition, McGraw Hill (1989).

9. Hegde, U., Yuan, Z.-G., Hall, N., Fisher, J., and Litwiller, E., "Development of Waste Bag Air Flow and Drying Models for Solid Waste Management,” International Conference on Environmental Systems, August 2007.

10. Hyland, R. W., and Wexler, A., ASHRAE Trans., 89, 500-519, 1983. 


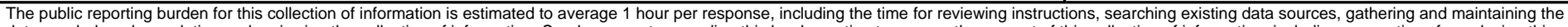

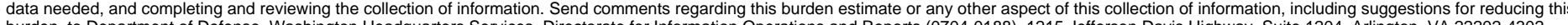

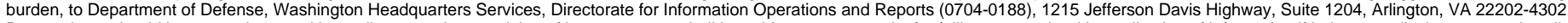

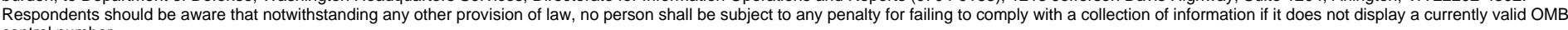

control number.
PLEASE DO NOT RETURN YOUR FORM TO THE ABOVE ADDRESS

\begin{tabular}{l|l|l}
$\begin{array}{l}\text { 1. REPORT DATE (DD-MM-YYYY) } \\
01-05-2012\end{array}$ & $\begin{array}{l}\text { 2. REPORT TYPE } \\
\text { Technical Memorandum }\end{array}$ & 3. DATES COVERED (FrOm - To) \\
\hline
\end{tabular}

4. TITLE AND SUBTITLE

Analysis of Water Extraction From Lunar Regolith

5a. CONTRACT NUMBER

NNC08BA08B

5b. GRANT NUMBER

5c. PROGRAM ELEMENT NUMBER

6. AUTHOR(S)

Hegde, U.; Balasubramaniam, R.; Gokoglu, S.

\section{5d. PROJECT NUMBER}

5e. TASK NUMBER

5f. WORK UNIT NUMBER

WBS 387498.04.01.05.02.03

7. PERFORMING ORGANIZATION NAME(S) AND ADDRESS(ES)

National Aeronautics and Space Administration

John H. Glenn Research Center at Lewis Field

Cleveland, Ohio 44135-3191

\section{SPONSORING/MONITORING AGENCY NAME(S) AND ADDRESS(ES)}

National Aeronautics and Space Administration

Washington, DC 20546-0001
8. PERFORMING ORGANIZATION REPORT NUMBER

E-18173

\section{DISTRIBUTIONIAVAILABILITY STATEMENT}

Unclassified-Unlimited

Subject Category: 31

Available electronically at http://www.sti.nasa.gov

This publication is available from the NASA Center for AeroSpace Information, 443-757-5802

\section{SUPPLEMENTARY NOTES}

\section{ABSTRACT}

Distribution of water concentration on the Moon is currently an area of active research. Recent studies suggest the presence of ice particles, and perhaps even ice blocks and ice-cemented regolith on the Moon. Thermal extraction of the in-situ water is an attractive means of satisfying water requirements for a lunar mission. In this paper, a model is presented to analyze the processes occurring during the heat-up of icy regolith and extraction of the evolved water vapor. The wet regolith is assumed to be present in an initially evacuated and sealed cell which is subsequently heated. The first step of the analysis involves calculating the gradual increase of vapor pressure in the closed cell as the temperature is raised. Then, in the second step, the cell is evacuated to low pressure (e.g., vacuum), allowing the water vapor to leave the cell and be captured. The parameters affecting water vapor pressure build-up and evacuation for the purpose of extracting water from lunar regolith are discussed in the paper. Some comparisons with available experimental measurements are also made.

\section{SUBJECT TERMS}

Water extraction; Hydrogen reduction; ISRU; Lunar regolith simulant; Lunar regolith; Lunar simulant

\begin{tabular}{|c|c|c|c|c|c|}
\hline \multicolumn{3}{|c|}{ 16. SECURITY CLASSIFICATION OF: } & \multirow{2}{*}{$\begin{array}{l}\text { 17. LIMITATION OF } \\
\text { ABSTRACT } \\
\text { UU }\end{array}$} & \multirow{2}{*}{$\begin{array}{l}\text { 18. NUMBER } \\
\text { OF } \\
\text { PAGES } \\
18\end{array}$} & \multirow{2}{*}{$\begin{array}{l}\text { 19a. NAME OF RESPONSIBLE PERSON } \\
\text { STI Help Desk (email:help@sti.nasa.gov) } \\
\text { 19b. TELEPHONE NUMBER (include area code) } \\
\text { 443-757-5802 }\end{array}$} \\
\hline $\begin{array}{l}\text { a. REPORT } \\
U\end{array}$ & $\begin{array}{l}\text { b. ABSTRACT } \\
\mathrm{U}\end{array}$ & $\begin{array}{l}\text { c. THIS } \\
\text { PAGE } \\
\text { U }\end{array}$ & & & \\
\hline
\end{tabular}



